\title{
The influence factors of mean particle size and positive quality control of
}

\author{
bacterial filtration efficiency system
}

Yayi Yi* , Dianlong Shi

Qingdao Junray Intelligent Instrument Co.,Ltd., Qingdao, 266237, PR China

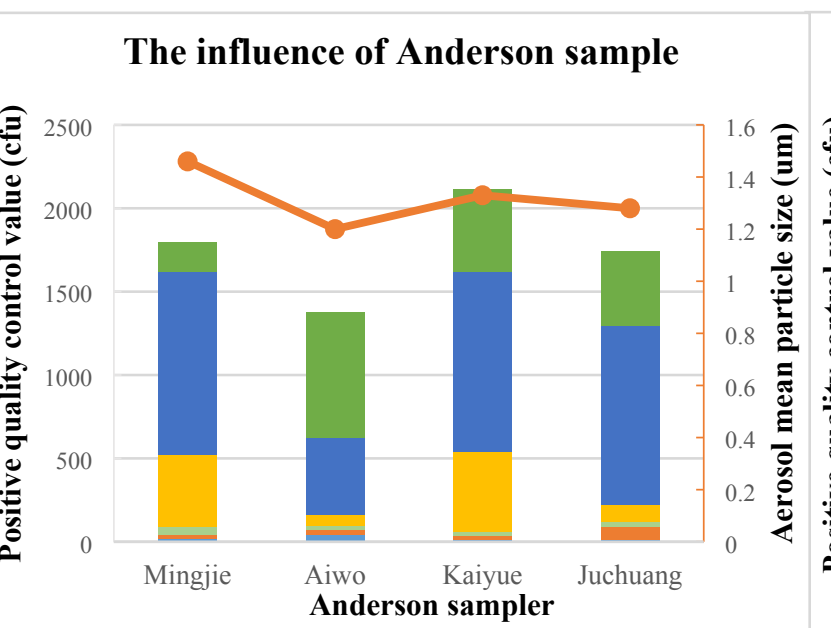

The influence of spray flow

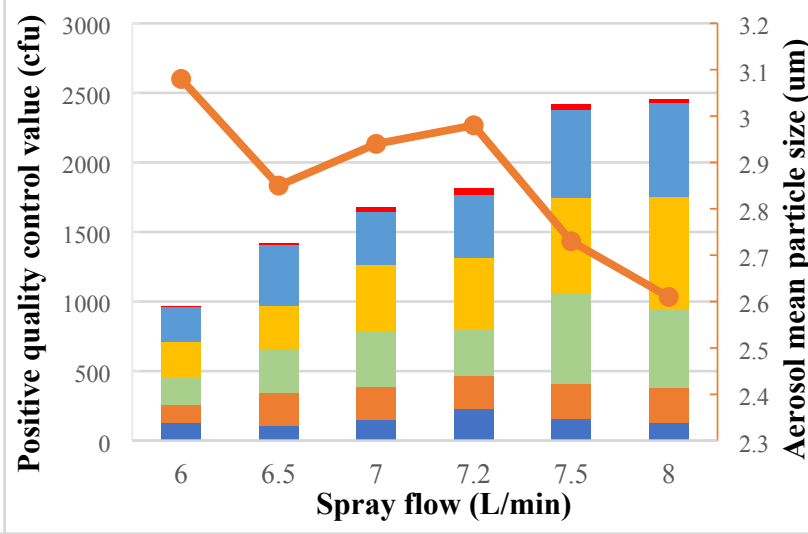

The influence of medium thickness

The influence of peristaltic pump flow

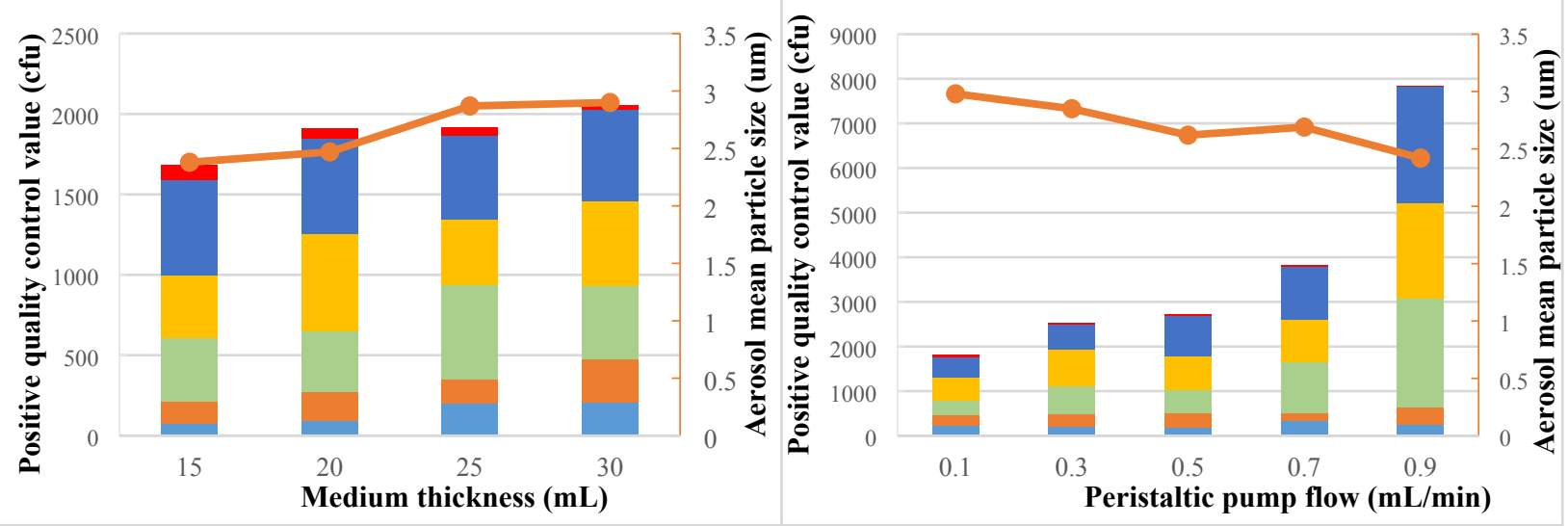

\section{Summary}

Background: The Coronavirus Disease 2019 (COVID-19) has swept the whole world with high mortality. Since aerosol transmission is the main route of transmission, wearing a mask serves as a crucial preventive measure. An important parameter to evaluate the performance of a mask is the bacteria filtration efficiency (BFE). Aerosol mean particle size (MPS) and positive quality control value are two key indexes of BFE 
system.

Aim: To study the major influence factors of the mean particle size of bacterial aerosols and positive quality control value of BFE system.

Method and Results: In this study, we investigated the influence of Anderson sampler, spray flow, medium thickness, and peristaltic pump flow on the MPS of bacterial aerosols and positive quality control value of BFE system, respectively. The results show that the machining accuracy of Anderson sampler has great influence on aerosol MPS and positive quality control value. With the increase of aerosol spray flow rate, the positive quality control value will increase gradually, but the effect on aerosol MPS is not a simple linear relationship. As the agar medium thickness increased, the positive quality control value and aerosol MPS increased gradually. With the increase of peristaltic pump flow, the positive quality control value increased gradually, while the aerosol MPS was basically in a downward trend. When the peristatic pump flow rate was $0.1 \mathrm{~mL} / \mathrm{min}$, the spray flow rate was $7.2 \mathrm{~L} / \mathrm{min}$, the agar plate thickness was $27 \mathrm{~mL}$, and the Anderson sampler of Beijing Mingjie was used for the experiment, the aerosol MPS and positive quality control value were both within the acceptable range and were the optimal parameters.

Conclusions: This study provides guidance for the manufacturers of the BFE system and improves the protective performance of masks, which is important for the human health, especially during the occurrence of viral pandemics such as "COVID-19".

Key word: COVID-19; Mask; BFE system; MPS; Positive quality control value 


\section{Introduction}

In December 2019, an outbreak of the Coronavirus Disease 2019 (COVID-19) occurred in the city of Wuhan, China. The COVID-19 has hit all regions in China and almost all countries worldwide at an unprecedented transmission rate, and was declared as a Public Health Emergency of International Concern (PHEIC) by the World Health Organization (WHO) ${ }^{[1]}$. The occurrence of viral pandemics with extensive transmission and the associated health impact is a big concern around the globe, which raises the importance of respiratory protection against the viral transmission. Aerosol transmission is the main routes of COVID-19 transmission. Coughing, sneezing, and talking can transmits microbial aerosols through the air, potentially carrying infectious diseases ${ }^{[2]}$. The associated risk can be exacerbated when pathogenic microbials including bacteria and virus are present in the air ${ }^{[3,4]}$. The role of respiratory protection becomes particularly important in the occurrence of viral pandemics such as "COVID19", SARS, and H1N1 influenza ${ }^{[3-6]}$.

Mask has been used for more than 100 years to prevent the spread of respiratory infectious diseases and surgical infections ${ }^{[7-11]}$. The role of mask is to prevent harmful aerosols from the human body instead of being inhaled into the lungs, including dust, smoke, bacteria, and virus. Using masks to prevent viral transmission has been recommend by many international guidelines ${ }^{[12-14]}$. MacIntyre et al. ${ }^{[15]}$ reported that masks can reduce the risk of influenza infection significantly. Brienen et al. ${ }^{[16]}$ showed that population-wide use of face masks could make an important contribution in delaying an influenza pandemic. Van der Sande et al. ${ }^{[17]}$ have indicated that the 
protective factor of surgical masks was 4.1-5.3, while the protective factor of homemade masks was $2.2-2.5$, which could reduce the respiratory infections of the population to a certain extent. With the outbreak of "COVID-19", the disposable masks are in short supply, and the demand for masks bacterial filtration efficiency detector is rising rapidly ${ }^{[18]}$. From 20 Jan 2020 to 30 Jun 2020, the largest daily facemask shortages in China were predicted to be $589.5,49.3$, and 37.5 million in the maskwearing policy in all regions of mainland, the mask-wearing policy only in Hubei province, and the non-implementation of the mask-wearing policy in other region, respectively $[19,20]$.

An important parameter to evaluate the performance of a mask is the bacteria filtration efficiency (BFE) ${ }^{[21]}$. BFE refers to the percentage of the respirator material filtered out of the bacteria-containing suspended particles under the specified flow rate, which reflects the filtration quality of the respirator. The protective performance of a mask mainly depends on the filtration efficiency of the mask. How to ensure the mean particle size (MPS) of bacterial aerosols and the positive quality control value are the most critical indicators of the mask BFE detector, and is also the current research hotspots ${ }^{[22]}$. In this study, the major influence factors of the MPS and positive quality control value of the BFE system were investigated, including Anderson sampler, spray flow, medium thickness, and peristaltic pump flow, which provides guidance for the manufacturers of the BFE detector and improve the protective performance of masks under the pandemics of COVID-19. 


\section{Materials and methods}

\section{Materials}

Tryptic soy agar (TSA), tryptic soy broth (TSB), peptone water, staphylococcus aureus ATCC6538, petri dish ( $\$ 90 \mathrm{~mm}$ ), and vaccination ring.

\section{Equipment}

High pressure steam sterilization pot $\left(121^{\circ} \mathrm{C} \sim 123^{\circ} \mathrm{C}\right)$, incubator (constant temperature $37^{\circ} \mathrm{C} \pm 2^{\circ} \mathrm{C}$ ), vortex type vortex mixer (up to $16 \mathrm{~mm} \times 150 \mathrm{~mm}$ tube), orbital vibrator $(100 \mathrm{r} / \mathrm{min} \sim 250 \mathrm{r} / \mathrm{min})$, refrigerator $\left(2^{\circ} \mathrm{C} \sim 8^{\circ} \mathrm{C}\right)$, bacteria filtration efficiency detector (ZR-1000, Qindao Junray Intelligent Instrument Co., Ltd), and colony counter (ZR-1100, Qindao Junray Intelligent Instrument Co., Ltd).

\section{Experimental methods}

\section{Determination method of bacterial suspension concentration}

A strain of staphylococcus aureus was vaccinated into $100 \mathrm{~mL}$ TSB, then exposed to an incubator under $100 \mathrm{r} / \mathrm{min}$ at $37^{\circ} \mathrm{C}$. After $24 \mathrm{~h}$, the bacterial suspension was obtained. $1 \mathrm{~mL}$ bacterial suspension was added to the test tube with $9 \mathrm{~mL}$ peptone solution $(1.5 \%)$, then diluted step by step to $10^{-7}$, and $0.1 \mathrm{~mL}$ diluted bacterial suspension from $10^{-5}$ to $10^{-7}$ test tubes was added to TSA plate for culture. Two parallel plates were made for each gradient, then put them into the incubator at $37^{\circ} \mathrm{C}$ for $24 \mathrm{~h}$.

Statistic the bacterial count of each TSA plate, then take the colony number of ( 0 100) CFU flat gradient to count, and the concentration of bacteria suspension 
concentrate can be calculated. Then diluted $1 \mathrm{~mL}$ bacteria suspension to about $5 \times 10^{5}$

$\mathrm{CFU} / \mathrm{mL}$, and $20 \mathrm{~mL}$ of which were prepared.

\section{Positive quality control value calculation}

Perform a positive control run without a test specimen by BFE detector. Initiate the bacterial suspension by turning on the vacuum pump and adjust the flow rate through the Anderson sampler to $28.3 \mathrm{~L} / \mathrm{min}$. Deliver the bacterial suspension by the peristaltic pump for $1 \mathrm{~min}$. Sampling for $2 \mathrm{~min}$, and the bacteria aerosols were collected on agar medium. Agar plate were cultivated in the incubator at $(37 \pm 2)^{\circ} \mathrm{C}$ for $(24 \pm 4) \mathrm{h}$, then count the number of staphylococcus aureus colonies on each plate, and use the "positive hole" conversion table in accordance with the instructions of the Anderson sampler manufacturer for stages 3 to 6 . The sum of staphylococcus aureus colonies on each stage is a positive quality control value of detector, and take the mean of the two totals for two positive control runs. ASTM F2101-2014 Evaluating the bacterial filtration efficiency (BFE) of medical face mask materials, using a biological aerosol of staphylococcus aureus [23] and BS EN 14683:2019 Medical face masks Requirements and test methods ${ }^{[24]}$ specifies, positive quality control value should be within the scope of the (1700-3000) CFU.

\section{Bacterial aerosol MPS calculation}

After sampling, the agar medium were cultivated in the incubator at $(37 \pm 2)^{\circ} \mathrm{C}$ for $(24 \pm 4)$ h. From the positive control plates, the MPS of bacterial aerosol was calculated using the formula (1). BS EN 14683:2019 Medical face masks - Requirements and test methods ${ }^{[24]}$ and YY0469-2011 Medical surgical masks technical requirements ${ }^{[25]}$ rules, 
the MPS should be within the scope of $(3.0 \pm 0.3)$ um.

$$
M P S=\frac{(P 1 \times C 1)+(P 2 \times C 2)+(P 3 \times C 3)+(P 4 \times C 4)+(P 5 \times C 5)+(P 6 \times C 6)}{C 1+C 2+C 3+C 4+C 5+C 6}
$$

Table 1 Anderson sampler particle size and colony count at all levels.

\begin{tabular}{|l|l|l|l|l|l|l|}
\hline Stage number & 1 & 2 & 3 & 4 & 5 & 6 \\
\hline Size of particle & P1 & P2 & P3 & P4 & P5 & P6 \\
\hline Viable "particle" plate count & C1 & C2 & C3 & C4 & C5 & C6 \\
\hline
\end{tabular}

Where $\mathrm{P} 1=7.00 \mathrm{um} ; \mathrm{P} 2=4.70 \mathrm{um} ; \mathrm{P} 3=3.30 \mathrm{um} ; \mathrm{P} 4=2.10 \mathrm{um} ; \mathrm{P} 5=1.10 \mathrm{um} ; \mathrm{P} 6=0.65 \mathrm{um}$.

$\mathrm{C} 1+\mathrm{C} 2+\mathrm{C} 3+\mathrm{C} 4+\mathrm{C} 5+\mathrm{C} 6$ refer to positive quality control value.

\section{Results and discussion}

\section{The influence of Anderson sampler}

Four Anderson sampler from different manufacturers were selected to compare

142 the influence of Anderson sampler in the aerosol MPS and positive quality control value,

143 including Beijing Mingjie, Qingdao Kaiyue, Qingdao Juchuang and Weifang Aiwo.

144 The experiment condition was set as: the peristaltic pump flow is $0.1 \mathrm{~mL} / \mathrm{min}$, the spray

145 flow is $10 \mathrm{~L} / \mathrm{min}$, and agar medium thickness is $15 \mathrm{~mL}$. Positive quality control values

146 and aerosol MPS with different Anderson sampler manufacturer were shown in Table

2.

148 By comparing and testing the Anderson sampler from different manufacturers, it 149 is found that the aerosol MPS and positive quality control value calculated from the 
experimental results of the Anderson sampler from different manufacturers is different under the same experimental conditions. The positive quality control value of other three experiments were all within the scope of (1700-3000) CFU except using the Weifang Aiwo's Anderson sampler. The order of aerosol MPS is Beijing Mingjie > Qingdao Kaiyue > Qingdao Juchuang > Weifang Aiwo, so the Beijing Mingjie' Anderson sampler was recommended. The design principle of Anderson sampler is as follows: when microbial aerosols pass through a nozzle or jet stream, they shoot at the front impingement plate (or the surface of the medium) according to the principle of inertia, deflecting the airflow $90^{\circ} \sim 180^{\circ}$. Particles of sufficient momentum, acting by inertia, move in a straight line in the original direction without following the deflection of the fluid, and are collected by impingement on the collecting plate (or on the surface of the medium). Smaller particles can follow the fluid along the streamline under the air flow without crashing down, and these bacteria-bearing particles will slip off or escape because of their small inertia. The Anderson sampler can divide the bacterial aerosol into two parts. Particles larger than a certain aerodynamic diameter can crash down from the airflow, and smaller particles can escape with the aerosol fluid passing through the sampler. As each manufacturer has different requirements for pore accuracy, the size of bacterial aerosol captured by Anderson sampler of each manufacturer is also different, so the calculated aerosol MPS is also different. The pore size and capture particles range of Anderson sampler is shown in Table 3.

Table 2 Positive quality control values and aerosol MPS with different Anderson 
sampler manufacturer.

\begin{tabular}{|c|c|c|c|c|}
\hline Sampler & \multicolumn{2}{|c|}{ Bejing Mingjie } & \multicolumn{2}{|c|}{ Weifang Aiwo } \\
\hline $\begin{array}{c}\text { Peristaltic pump } \\
\text { flow }\end{array}$ & \multicolumn{2}{|c|}{$0.1 \mathrm{~mL} / \mathrm{min}$} & \multicolumn{2}{|c|}{$0.1 \mathrm{~mL} / \mathrm{min}$} \\
\hline Spray flow & \multicolumn{2}{|c|}{$10 \mathrm{~L} / \mathrm{min}$} & \multicolumn{2}{|c|}{$10 \mathrm{~L} / \mathrm{min}$} \\
\hline Spray pressure & \multicolumn{2}{|c|}{$21.2 \mathrm{kPa}$} & \multicolumn{2}{|c|}{$21.2 \mathrm{kPa}$} \\
\hline Tablet thickness & \multicolumn{2}{|c|}{$15 \mathrm{~mL}$} & \multicolumn{2}{|c|}{$15 \mathrm{~mL}$} \\
\hline The layer number & $\begin{array}{l}\text { The positive } \\
\text { pole count (r) }\end{array}$ & $\begin{array}{l}\text { Viable "particle" } \\
\text { plate count }(\mathrm{C})\end{array}$ & $\begin{array}{l}\text { The positive } \\
\text { pole count (r) }\end{array}$ & $\begin{array}{l}\text { Viable "particle" } \\
\text { plate count }(\mathrm{C})\end{array}$ \\
\hline 1 & 19 & 19 & 40 & 40 \\
\hline 2 & 25 & 25 & 34 & 34 \\
\hline 3 & 43 & 45 & 23 & 24 \\
\hline 4 & 265 & 434 & 60 & 65 \\
\hline 5 & 374 & 1093 & 274 & 462 \\
\hline 6 & 144 & 179 & 339 & 752 \\
\hline $\begin{array}{l}\text { Positive quality } \\
\text { control value }\end{array}$ & l & 1795 & l & 1377 \\
\hline MPS & & 1.46 & & 1.20 \\
\hline
\end{tabular}

\begin{tabular}{|c|c|c|c|}
\hline Sampler & Qingdao Kaiyue & \multicolumn{2}{|c|}{ Qingdao Juchuang } \\
\hline $\begin{array}{c}\text { Peristaltic pump } \\
\text { flow }\end{array}$ & $0.1 \mathrm{~mL} / \mathrm{min}$ & \multicolumn{2}{|c|}{$0.1 \mathrm{~mL} / \mathrm{min}$} \\
\hline Spray flow & \multicolumn{2}{|c|}{$10 \mathrm{~L} / \mathrm{min}$} & \multicolumn{2}{|c|}{$10 \mathrm{~L} / \mathrm{min}$} \\
\hline Spray pressure & $20.8 \mathrm{kPa}$ & \multicolumn{2}{|c|}{$20.8 \mathrm{kPa}$} \\
\hline Tablet thickness & \multicolumn{2}{|c|}{$15 \mathrm{~mL} \mathrm{~mL}$} \\
\hline The layer number & $\begin{array}{c}\text { The positive } \\
\text { pole count (r) }\end{array}$ & $\begin{array}{c}\text { Viable "particle" plate count (C) } \\
\text { plate count (r) }\end{array}$ & $\begin{array}{c}\text { The positive } \\
\text { pole counte count (C) }\end{array}$ \\
\hline
\end{tabular}


bioRxiv preprint doi: https://doi org/10.1101/2021.12.20.473569; this version posted December 20, 2021. The copyright holder for this preprint (which was not certified by peer review) is the author/funder, who has granted bioRxiv a license to display the preprint in perpetuity. It is made available under aCC-BY 4.0 International license.

\begin{tabular}{|c|c|c|c|c|}
\hline 1 & 13 & 13 & 10 & 10 \\
\hline 2 & 23 & 23 & 81 & 29 \\
\hline 3 & 22 & 23 & 88 & 99 \\
\hline 4 & 280 & 482 & 373 & 1078 \\
\hline 5 & 370 & 1078 & 269 & 447 \\
\hline 6 & 283 & 492 & $/$ & 1.28 \\
\hline $\begin{array}{c}\text { Positive quality } \\
\text { control value }\end{array}$ & 1 & 2069 & & \\
\hline \begin{tabular}{c} 
MPS \\
\hline
\end{tabular} & & 1.33 & & \\
\hline
\end{tabular}

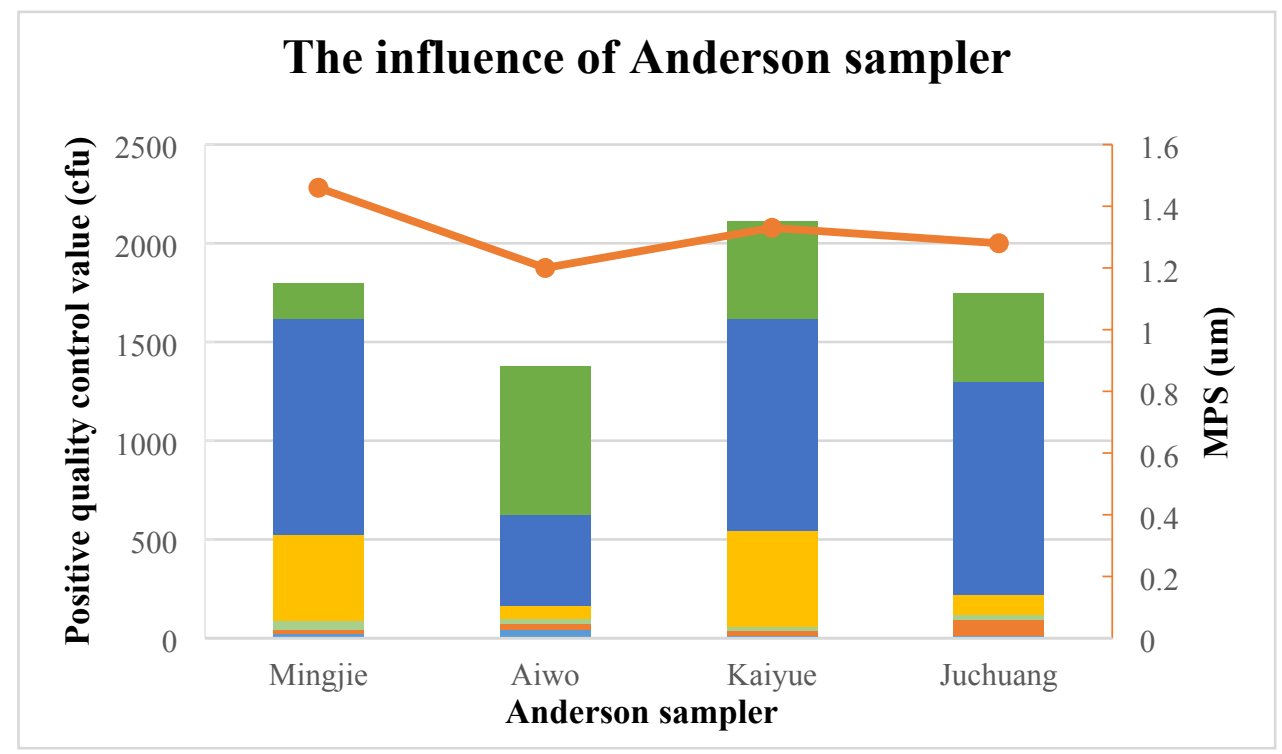

176 Figure 1 The relationship of Anderson sampler with positive quality control value and

177 aerosol MPS (Histogram represents positive quality control value, broken line 178 represents aerosol MPS). 
bioRxiv preprint doi: https://doi.org/10.1101/2021.12.20 473569; this version posted December 20, 2021. The copyright holder for this preprint (which was not certified by peer review) is the author/funder, who has granted bioRxiv a license to display the preprint in perpetuity. It is made available under aCC-BY 4.0 International license.
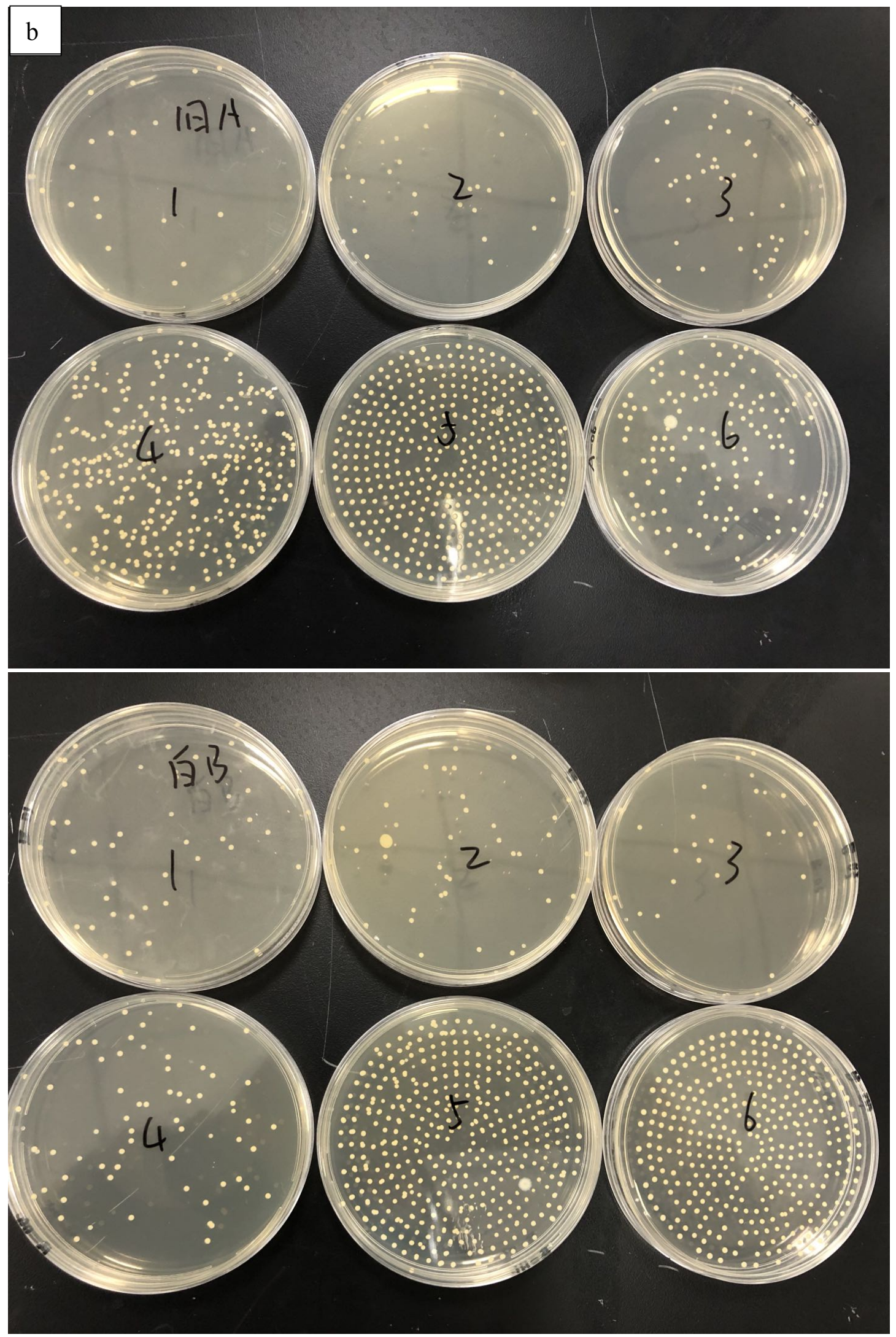
bioRxiv preprint doi: https://doi.org/10.1101/2021.12.20.473569; this version posted December 20, 2021. The copyright holder for this preprint (which was not certified by peer review) is the author/funder, who has granted bioRxiv a license to display the preprint in perpetuity. It is made available under aCC-BY 4.0 International license.
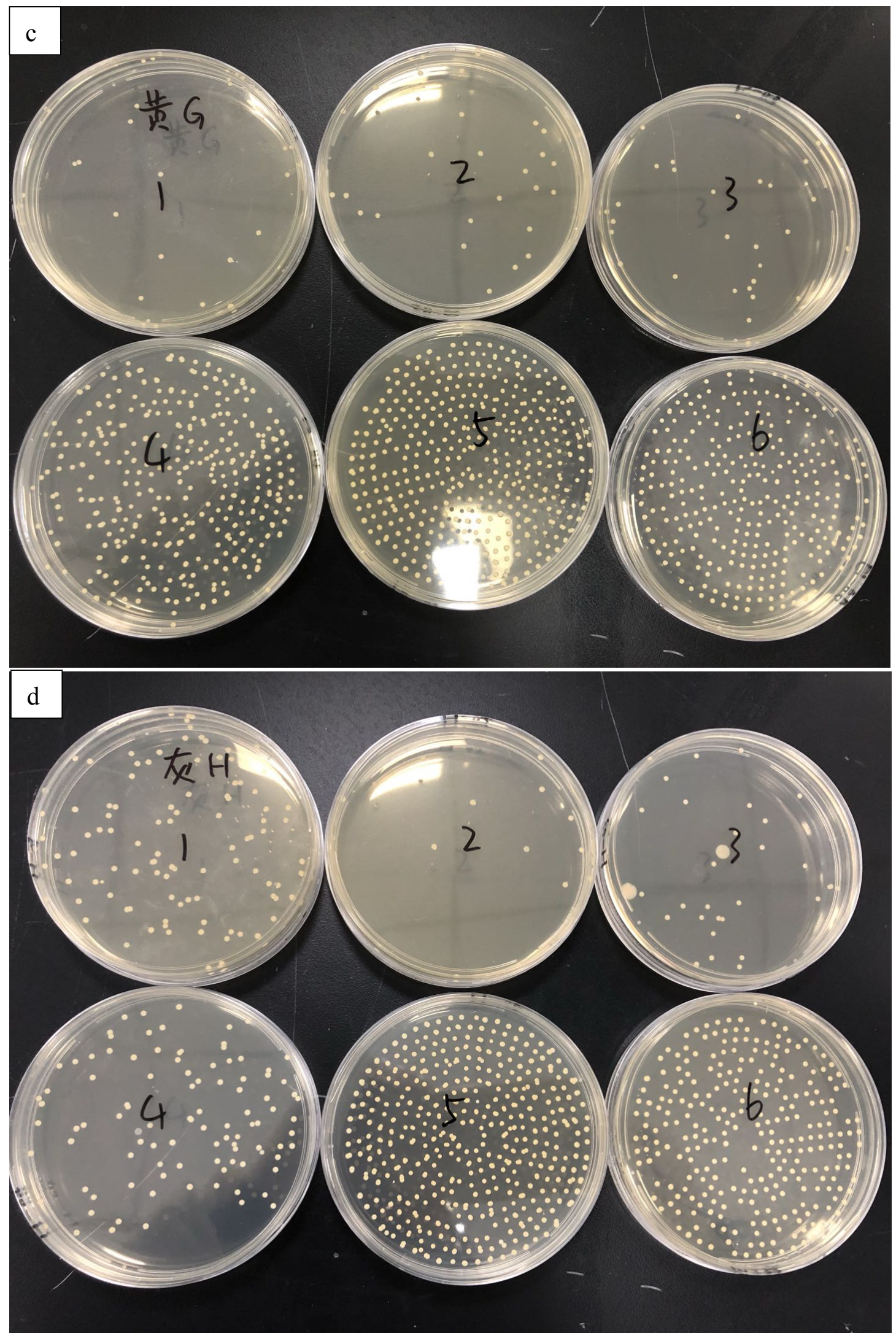

184 Figure 2 The experimental results of different Anderson sampler (a for Beijing Mingjie,

b for Weifang Aiwo, c for Qingdao Kaiyue, d for Qingdao Juchuang). 
187 Table 3 The pore size and scope of capture particles of Anderson sampler.

\begin{tabular}{ccc}
\hline Anderson sampler stages & Pore size $(\mathrm{mm})$ & The scope of capture particles (um) \\
\hline Stage 1 & 1.18 & $>7.0$ \\
Stage 2 & 0.91 & $4.7 \sim 7.0$ \\
Stage 3 & 0.71 & $3.3 \sim 4.7$ \\
Stage 4 & 0.53 & $2.1 \sim 3.3$ \\
Stage 5 & 0.34 & $1.1 \sim 2.1$ \\
Stage 6 & 0.25 & $0.65 \sim 1.1$ \\
\hline
\end{tabular}

188 
spray flow rate is $7.2 \mathrm{~L} / \mathrm{min}$, the MPS is maximum and the flow for this sprayer is the most appropriate option on the premise of meeting the standard value of positive quality control. The mean aerosol particles depend on comprehensive influence, including the

205 size of the sprayer, spray flow rate, flow of peristaltic pump, physical properties of 206 bacteria aerosol, pore diameter, the relative position and angle of fluid pore in mixing 207 chamber of sprayer, so the appropriate spray flow will be different for every sprayer 208 due to very slight error on each sprayer processing.

210 Table 4 Positive quality control values and aerosol MPS at different spray flow rates.

\begin{tabular}{cccc}
\hline Number & $\begin{array}{c}\text { Spray flow } \\
(\mathrm{L} / \mathrm{min})\end{array}$ & $\begin{array}{c}\text { Positive quality control } \\
\text { value }(\mathrm{CFU} / \mathrm{mL})\end{array}$ & Aerosol MPS (um) \\
\hline 1 & 6.0 & 964 & 3.08 \\
2 & 6.5 & 1419 & 2.85 \\
3 & 7.0 & 1679 & 2.94 \\
4 & 7.2 & 1814 & 2.98 \\
5 & 7.5 & 2420 & 2.73 \\
6 & 8.0 & 2457 & 2.61 \\
\hline
\end{tabular}




\section{The influence of spray flow}

213 Figure 3 The relationship of spray flow with positive quality control value and aerosol

214 MPS (Histogram represents positive quality control value, broken line represents aerosol MPS).

\section{The influence of agar medium thickness}

Different agar medium thickness of $15,20,25$, and $30 \mathrm{~mL}$ were prepared to

quality control value. The experiment condition was set as: the peristaltic pump flow is was selected.

The positive quality control values and aerosol MPS under different medium thickness were shown in Table 5. As the agar medium thickness increased, both the positive quality control value and aerosol MPS increased gradually (Figure 4). When the agar medium thickness was $25 \mathrm{~mL}$ or $30 \mathrm{~mL}$, the MPS could meet the requirement 
228 efficiency. The aerosol particles cannot come down if the distance is too far, while it is

229 difficult to operate with short distance. The impact distance of the Anderson sampler is

230 about $2.5 \mathrm{~mm}$. When the sampler structure is fixed, the thickness of the agar medium in

231 the plate determines the impact distance. Adding 24, 27 and 30mL agar medium to the

232 petri dish, respectively, and their impact distances were $3,2.5$ and $2.0 \mathrm{~mm}$. But the

233 percentage distribution of the three impact distance particles in the six nodes was

234 roughly similar. Therefore, Ranz and Wong ${ }^{[26]}$ recommend that adding $27 \mathrm{~mL}$ agar

235 medium into Anderson sampler is optimal.

236

237 Table 5 Positive quality control values and aerosol MPS under different medium

238 thickness.

\begin{tabular}{cccc}
\hline Number & $\begin{array}{r}\text { Medium thickness } \\
(\mathrm{mL})\end{array}$ & $\begin{array}{c}\text { Positive quality control } \\
\text { value }(\mathrm{CFU} / \mathrm{mL})\end{array}$ & Aerosol MPS (um) \\
\hline 1 & 15 & 1685 & 2.38 \\
2 & 20 & 1907 & 2.47 \\
3 & 25 & 1917 & 2.87 \\
4 & 30 & 2053 & 2.90 \\
\hline
\end{tabular}




\section{The influence of medium thickness}

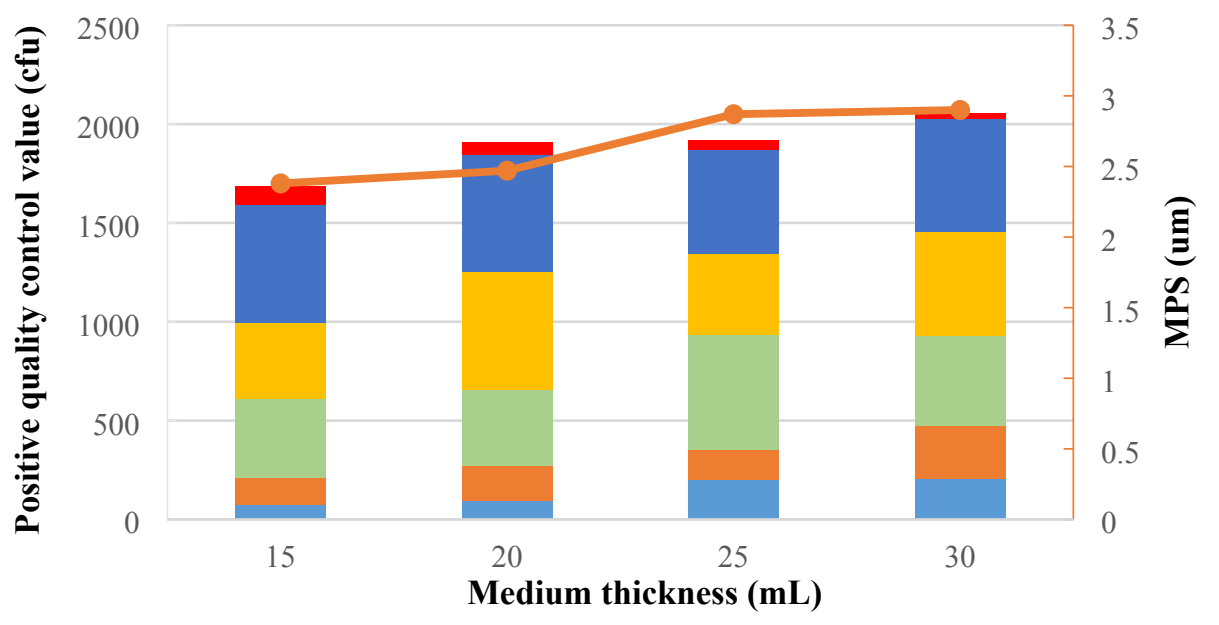

241 Figure 4 The relationship of medium thickness with positive quality control value and

242 aerosol MPS (Histogram represents positive quality control value, broken line represents aerosol MPS).

\section{The influence of peristaltic pump flow}

Different peristaltic pump flow rate was selected to compare the influence of peristaltic pump flow in the aerosol MPS and positive quality control value, including is $7.2 \mathrm{~L} / \mathrm{min}$, agar medium thickness is $25 \mathrm{~mL}$, and Beijing Mingjie' Anderson sampler was selected.

The positive quality control values and aerosol MPS under different peristaltic pump flow were shown in Table 6. With the increase of peristaltic pump flow, the positive quality control value gradually increased, while the aerosol MPS was basically in a downward trend (Figure 5). When the peristaltic pump flow was $0.1 \mathrm{~mL} / \mathrm{min}$, the 
256 quantity of bacterial aerosols entering the sprayer increased with the peristaltic pump

257 flow under the same spray flow. However, small particle aerosols produced far more

258 than large particles of bacterial aerosols, so the MPS of aerosols in a downtrend

259 basically although the positive quality value increases gradually. Therefore, we suggest

260 that the peristaltic pump flow of $0.1 \mathrm{~mL} / \mathrm{min}$ is the most appropriate option.

262 Table 6 Positive quality control values and aerosol MPS under different peristaltic 263 pump flow.

\begin{tabular}{cccc}
\hline Number & $\begin{array}{r}\text { Peristaltic pump flow } \\
(\mathrm{mL} / \mathrm{min})\end{array}$ & $\begin{array}{c}\text { Positive quality control } \\
\text { value }(\mathrm{CFU} / \mathrm{mL})\end{array}$ & Aerosol MPS (um) \\
\hline 1 & 0.1 & 1814 & 2.98 \\
2 & 0.3 & 2523 & 2.85 \\
3 & 0.5 & 2723 & 2.62 \\
4 & 0.7 & 3821 & 2.69 \\
5 & 0.9 & 7842 & 2.42 \\
\hline
\end{tabular}

\section{The influence of peristaltic pump flow}

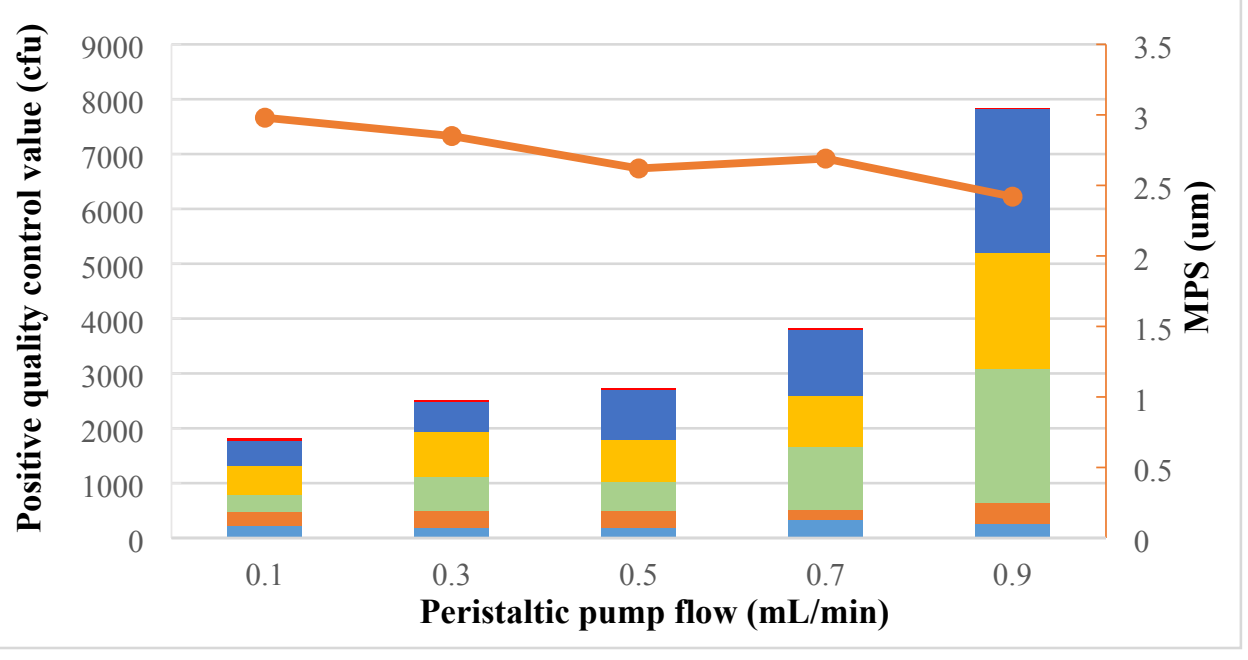

266 Figure 5 The relationship of peristaltic pump flow with positive quality control value 
and aerosol MPS (Histogram represents positive quality control value, broken line represents aerosol MPS).

\section{Conclusion}

The mask BFE is one of the key indicators for detecting masks. The aerosol MPS

279 linear relationship. As agar medium thickness increased, the positive quality control

280 value and aerosol MPS increased gradually. With the increase of peristaltic pump flow,

281 the positive quality control value increased gradually, while the aerosol MPS was

282 basically in a downward trend. When the peristatic pump flow rate was $0.1 \mathrm{~mL} / \mathrm{min}$, the

283 spray flow rate was $7.2 \mathrm{~L} / \mathrm{min}$, the agar medium thickness was $27 \mathrm{~mL}$, and the Anderson

284 sampler of Beijing Mingjie was used for the experiment, the positive quality control

285 value and aerosol MPS were both within the acceptable range and were the optimal

286 parameters. This study provides guidance for manufacturers of BFE detector and

287 theoretical basis for testing institutions to test the BFE of masks, which is important for

288 the human health, especially during the occurrence of viral pandemics such as 
"COVID-19".

\section{References}

1. WHO. Statement on the Second Meeting of the International Health Regulations (2005) Emergency Committee Regarding the Outbreak of Novel Coronavirus(2019-nCoV); 2020.

2. Seojin Jung, Jaejin An, Hyungjin Na and Jooyoun Kim. Surface Energy of Filtration Media Influencing the Filtration Performance against Solid Particles, Oily Aerosol, and Bacterial Aerosol. Polymers. 2019; 11:935.

3. Yan, D.; Zhang, T.; Su, J.; Zhao, L.-L.; Wang, H.; Fang, X.-M.; Zhang, Y.-Q.; Liu, H.-Y.; Yu, L.-Y. Structural variation in the bacterial community associated with airborne particulate matter in Beijing, China, during Hazy and Nonhazy Days. Appl. Environ. Microbiol. 2018; 84, e00004-18.

4. Duquenne, P.; Marchand, G.; Duchaine, C. Measurement of endotoxins in bioaerosols at workplace: A critical review of literature and a standardization issue. Ann. Occup. Hyg. 2013; $57,137-172$.

5. Ali, M.U.; Liu, G.; Yousaf, B.; Ullah, H.; Abbas, Q.; Munir, M.A.M. A systematic review on global pollution status of particulate matter-associated potential toxic elements and health perspectives in urban environment. Environ. Geochem. Health 2018; 1-32.

6. Prussin, A.J.; Garcia, E.B.; Marr, L.C. Total concentrations of virus and bacteria in indoor and outdoor air. Environ. Sci. Technol. Lett. 2015; 2, 84-88.

7. Lai, A.C.K.; Poon, C.K.M.; Cheung, A.C.T. Effectiveness of facemasks to reduce exposure hazards for airborne infections among general populations. J. R. Soc. Interface 2012; 9, 938 948.

8. Makison Booth, C.; Clayton, M.; Crook, B.; Gawn, J.M. Effectiveness of surgical masks against influenza bioaerosols. J. Hosp. Infect. 2013; 84, 22-26.

9. Rengasamy, A.; Zhuang, Z.; Berryann, R. Respiratory protection against bioaerosols: Literature review and research needs. Am. J. Infect. Control 2004; 32, 345-354.

10. Rubino, I.; Choi, H.J. Respiratory protection against pandemic and epidemic diseases. Trends Biotechnol. 2017; 35, 907-910.

11. Sublett, J.L. Effectiveness of air filters and air cleaners in allergic respiratory diseases: A review of the recent literature. Curr. Allergy Asthma Rep. 2011; 11, 395-402.

12. National plan for the prevention and control of influenza pandemic. Paris: General Secretariat for National Defence;2007.

13. Australian health management plan for pandemic influenza: important information for all Australians. Canberra: Department of Health and Ageing, Commonwealth of Australia; 2006.

14. Department of Health and Human Services. HHS pandemic influenza plan. Washington: The Department; 2005.

15. MacIntyre CR, Cauchemez S, Dwyer DE, Seale H, Cheung P, Browne G, et al. Face Mask Use and Control of Respiratory Virus Transmission in Households. Emerg Infect Dis. 2009; 15(2):233-41.

16. Brienen NCJ, Timen A, Wallinga J, Van Steenbergen JE, Teunis PFM. The Effect of Mask Use on the Spread of Influenza During a Pandemic. RISK ANAL. 2010; 30(8):1210-8.

17. Van der Sande M, Teunis P, Sabel R. Professional and home-made face masks reduce exposure to respiratory infections among the general population. PLOS ONE. 2008 2008-01-01; 3(7): 
e2618.

18. Sana Ullah, Azeem Ullah, Jaeyun Lee, Yeonsu Jeong, Motahira Hashmi, Chunhong Zhu, KyeII Joo, Hyung Joon Cha, and Ick-Soo Kim. Reusability Comparison of Melt-Blown vs Nanofiber Face Mask Filters for Use in the Coronavirus Pandemic. ACS Applied nano materials. 2020; 3: 7231-7241.

19. $\mathrm{Wu} \mathrm{H}$, Huang J, et al. Facemask shortage and the novel coronavirus disease (COVID-19) outbreak: Reflections on public health measures. EClinicalMedicine. 2020:100329.

20. Hou F, Zhou F, Xu X, Wang D, Xu G, Jiang T, et al. Personnel protection strategy for healthcare workers in Wuhan during the COVID-19 epidemic. Precision Clinical Medicine, 2020;3(3):169-174.

21. Dijia Wang, Yanjun You, Xiaoli Zhou, Zhiyong Zong, Hao Huang, Hui Zhang, Xin Yong, Yifan Cheng, Liu Yang, Qiong Guo, Youlin Long, Yan Liu, Jin Huang, Liang Du. Selection of homemade mask materials for preventing transmission of COVID-19: A laboratory study. PLOS ONE. 2020; 15(10): e0240285.

22. L.K.P. Suen, Y.P. Guo, S.S.K. Ho, C.H. Au-Yeung, S.C. Lam. Comparing mask fit and usability of traditional and nanofibre N95 filtering facepiece respirators before and after nursing procedures. J Hosp Infect. 2020; 104: 336-343.

23. ASTM F2101. Evaluating the bacterial filtration efficiency (BFE) of medical face mask materials, using a biological aerosol of staphylococcus aureus; 2014.

24. BS EN14683. Medical face masks. Requirements and test methods. London: The British Standards Institution; 2019.

25. YY0469. Medical surgical masks technical requirements; 2011.

26. May KR. Calibration of a modified Andersen bacterial aerosol sampler. Appl Microbiol. 1964; $12(1): 37$. 